\title{
Effects of Relative Column Width and Pile-Cap Elevation on Local Scour Depth around Complex Piers
}

\author{
M. Moreno'; R. Maia ${ }^{2}$; and L. Couto ${ }^{3}$
}

\begin{abstract}
An experimental campaign of 25 long-duration (13-47 days) laboratory tests was carried out with three complex pier models under steady clear-water flow conditions. Each model, characterized by a different relation between the column and the pile-cap widths, $D_{c} / D_{p c}$, was tested for a variety of pile-cap positions relatively to the initial bed, $H_{c}$. The experimental data were used to describe the temporal evolution of the scour depth as a function of $H_{c} / h(h=$ approach flow depth). The common criterion to stop experimental tests on complex piers was analyzed, and a new criterion was introduced. The equilibrium scour depth, $d_{s e}$, was calculated by extrapolation of data series. The results are used to evaluate the effect of $D_{c} / D_{p c}$ and $H_{c} / h$ on $d_{s e}$ when the pile cap is above the bed (Situation 1), partially buried in the bed (Situation 2), and completely buried in the bed (Situation 3). The analysis includes the definition of $H_{c}$ at which the maximum $d_{s e}$ occurs through an equation that takes into account the $D_{c} / D_{p c}$ ratio, the relative pile-cap thickness, $T / h$, and the column and pile-cap shapes. DOI: 10.1061/(ASCE)HY.1943-7900.0001080. ㅇ 2015 American Society of Civil Engineers.
\end{abstract}

Author keywords: Local scour; Complex pier; Bridge foundations; Equilibrium scour depth; Laboratory tests.

\section{Introduction}

Local scour around bridge foundations can lead to the partial failure or to the collapse of bridge piers and decks. Physical and economic considerations are increasingly leading to a significant number of new large bridge projects in which the use of specific support and foundation schemes is necessary. Those are often embodied by a column founded on a pile cap supported by an array of piles, a set commonly referred to as complex pier, similar to the one schematized in Fig. 1(a). Three basic situations may occur at the construction phase, corresponding to the pile cap being positioned above, on, or under the riverbed, as shown in Fig. 1(b). On the other hand, over the life of such a pier, not only the exposition of any of the three structural elements to the flow but also varying depths of resulting local scour below the surrounding bed levels can occur, as referred to by Coleman (2005).

The complexity of the local scour phenomenon at complex piers is due to the interaction of flow structure (i.e., downflow and horseshoe vortex) with the three elements of the pier generating new structures, as observed by Beheshti and Ataie-Ashtiani (2010). Research on scouring at complex piers is rather more recent than at single piers, with a small number of studies reported in the literature and thus requiring further research. Only three predictors of equilibrium scour depth, $d_{s e}$, at complex piers could be identified in the literature, i.e., Coleman (2005), Sheppard and Renna (2010), and

${ }^{1} \mathrm{Ph} . D$. Student, Dept. de Engenharia Civil, Faculdade de Engenharia, Univ. do Porto, Rua Dr. Roberto Frias, s/n, Porto 4200-465, Portugal (corresponding author). E-mail: dec10007@fe.up.pt; mcastiblanco@lnec.pt

${ }^{2}$ Associate Professor, Dept. de Engenharia Civil, Faculdade de Engenharia, Univ. do Porto, Rua Dr. Roberto Frias, s/n, Porto 4200465, Portugal. E-mail: rmaia@fe.up.pt

${ }^{3}$ Research Officer, Dept. de Hidræulica e Ambiente, Laboratório Nacional de Engenharia Civil, Av. do Brasil, 101, Lisbon 1700-066, Portugal. E-mail: lcouto@lnec.pt

Note. This manuscript was submitted on March 7, 2015; approved on July 9, 2015; published online on September 16, 2015. Discussion period open until February 16, 2016; separate discussions must be submitted for individual papers. This paper is part of the Journal of Hydraulic Engineering, (C) ASCE, ISSN 0733-9429/04015051(9)/\$25.00.
Arneson et al. (2012). Based on a specific scour experimental data campaign and taking also into account the existing data on the field accepted as of reference, the present work focuses on quantifying the influence of two of the most relevant dimensionless parameters - the relative column width, $D_{c} / D_{p c}\left(D_{c}=\right.$ column width; $D_{p c}=$ pile-cap width), and the relative pile-cap position, $H_{c} / h\left(H_{c}=\right.$ distance from the initial bed level to the top of the pile cap; $h=$ approach flow depth) —on the maximum local scour depth.

Experimental studies on the effect of geometry foundation on local scour for nonuniform piers include those of Jones et al. (1992) and Parola et al. (1996) on rectangular columns founded on rectangular caissons and of Melville and Raudkivi (1996) on cylindrical columns founded on cylindrical caissons. These authors concluded that the maximum scour depth depends on $D_{c} / D_{p c}$ and $H_{c}$. Moreover, Coleman (2005) suggested addressing the evaluation of local scour at complex piers as for a single pier, by establishing an equivalent diameter of the complex pier, $D_{e}$. In the situation when the pile cap is partially buried in the bed, $D_{e}$ was considered to be dependent on $D_{c} / D_{p c}$ and $H_{c}$. This procedure was recently modified by Ataie-Ashtiani et al. (2010) by considering also the influence of the pile-cap extension lengths (longitudinal and transversal distances of pile cap face out from the column face, $f_{l}$ and $f_{t}$ respectively). Sheppard and Rena (2010) and Arneson et al. (2012) presented a design chart to account for the shielding scouring effect due to the pile-cap extension lengths as function of $H_{c}$, based on the results of the studies performed by Jones (1989), Salim and Jones (1996), and Jones and Sheppard (2000).

\section{Experimental Setup and Procedure}

Experiments within the present study were carried out at the National Laboratory for Civil Engineering (LNEC) (Lisbon, Portugal), on a 40.0-m-long glass-sided rectangular tilting flume with a 2.0-m width and a 1.0-m-deep cross-section. Discharge was measured by an electromagnetic flow meter, positioned on the feeder pipe. At the inlet of the flume, a metallic grid was installed in order 


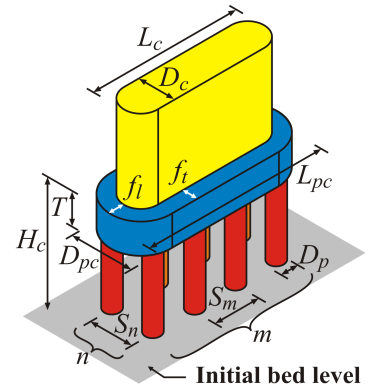

(a)
Situation 1 Situation 2 Situation 3

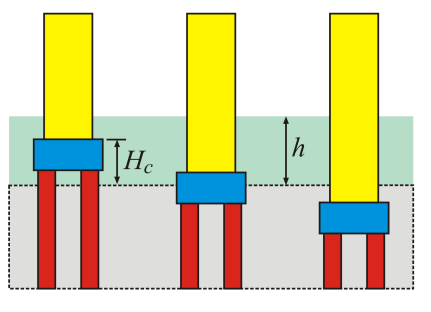

(b)
Fig. 1. Scheme of (a) complex pier geometry; (b) pile-cap situations analyzed

to guarantee that the transversal flow distribution is uniform. A concrete false bottom was installed in order to perform simultaneously two tests per run. Two 5-m-long and 0.40-m-deep recess boxes filled with sand were left in the false bottom. A 0.3 -m-thick and 0.2-m-long fine gravel mattress was embedded at the upstream end of the sand recess boxes, being leveled with the adjacent concrete bed, to avoid scouring at the transition with the sand bed. Complex pier models were placed at $\approx 2.0 \mathrm{~m}$ from the upstream border of the sand-bed recess boxes. At the downstream end of the flume, a sluice gate allowed the regulation of the water level inside the flume. Both recess boxes were filed with uniform quartz sand of median size $d_{50}=0.86 \mathrm{~mm}$ and geometric standard deviation (gradation coefficient) $\sigma_{g}=1.34$.

In order to achieve clear-water conditions, the experiments were carried out with constant-approach flow depth $(h=0.20 \mathrm{~m})$ and average flow discharge $(Q=103 \mathrm{l} / \mathrm{s})$, with flow intensity $U / U_{c} \approx 0.80$, where $U=0.258 \mathrm{~m} / \mathrm{s}$ and $U_{c}=0.322 \mathrm{~m} / \mathrm{s}$ are, respectively, the mean approach flow velocity and the critical flow velocity for the beginning of sediment motion. $U_{c}$ was obtained from Neill (1967)'s equation. The results of this equation fit the observations in the preliminary tests carried out within the study of Grimaldi et al. (2009) to evaluate conditions for the incipient motion of the bed material, with similar sediment and flow conditions, in the flume used in this study.

Three models of complex piers were tested. These models were designed with a rectangular round-nose column (built in concrete) founded on a rectangular round-nose pile cap (built in concrete), supported by an array of cylindrical piles (built in aluminum). The longitudinal axis of the complex pier models was aligned with the approach flow. The geometric characteristics of the three models are summarized in Table 1.

Prior to each experiment, after the complex pier model was installed in the recess box, the sand bed was compacted, and its surface was leveled with the adjacent concrete bed. The sand zone around the complex pier was covered with thin metallic plates to avoid uncontrolled scour at the beginning of the experiment. Then, the flume was slowly filled with water to allow air entrapped in the sediment to escape. The flow depth was regulated by adjusting the downstream sluice gate. Once the flow depth and the discharge were established, the metallic plates were carefully removed and the experiment started. The scour process was immediately initiated and the scour depth was measured, every 10 min during the first hour, to the accuracy of $\pm 0.1 \mathrm{~mm}$, with an adapted point gauge. Afterwards, the intervals between measurements increased and, after the first day, two or three measurements were carried out per day. The minimum duration of the experiments was 12 days. Depending on the test and scour time evolution, one, two, or the
Table 1. Complex Pier Geometry Characteristics

\begin{tabular}{lccc}
\hline Variable & Model 1 & Model 2 & Model 3 \\
\hline$D_{c}(\mathrm{~m})$ & 0.170 & 0.140 & 0.110 \\
$L_{c}(\mathrm{~m})$ & 0.493 & 0.463 & 0.433 \\
$f_{l}(\mathrm{~m})$ & 0.015 & 0.030 & 0.045 \\
$f_{t}(\mathrm{~m})$ & 0.015 & 0.030 & 0.045 \\
$D_{p c}(\mathrm{~m})$ & 0.200 & 0.200 & 0.200 \\
$L_{p c}(\mathrm{~m})$ & 0.523 & 0.523 & 0.523 \\
$T(\mathrm{~m})$ & 0.090 & 0.090 & 0.090 \\
$D_{p}(\mathrm{~m})$ & 0.050 & 0.050 & 0.050 \\
$m$ & 4 & 4 & 4 \\
$n$ & 2 & 2 & 2 \\
$S_{m}=S_{n}(\mathrm{~m})$ & 0.125 & 0.125 & 0.125 \\
\hline
\end{tabular}

three complex pier elements were in contact with the bed surface. For this reason, the point gauges were adapted to measure the scour depth in front of (1) the column; (2) the pile cap; and (3) one of the upstream piles. In the last case, the point gauge was inserted in a small hole drilled through the pile cap. In each test, the flow discharge values were recorded approximately every $5 \mathrm{~min}$ and the approach flow depth was verified at least twice a day. The variation of recorded flow discharge values was less than $1 \%$.

\section{Experimental Data and Results}

\section{Data Presentation and Characterization}

With the purpose of evaluating scouring effects around complex piers, 11 relative pile-cap positions in relation to the initial bed level were analyzed, henceforth referred as Positions A-K, corresponding to different ratios of $H_{c} / h$ (considered negative when the top of the pile cap is below the initial bed level), as included in Table 2. These 11 positions are associated with three typical situations [Fig. 1(b)]: (1) Positions A-D correspond to Situation 1, characterized by the bottom of the pile cap being above the initial bed level (i.e., $H_{c} / h>0.45$ for this study); (2) Positions E-H correspond to Situation 2, characterized by the pile cap being partially buried in the initial bed configuration (i.e., $0 \leq H_{c} / h \leq 0.45$ for this study); and (3) Positions I-K correspond to Situation 3, characterized by the pile cap being initially completely buried in the bed (i.e., $\left.H_{c} / h<0\right)$.

Table 3 summarizes the relevant characteristics of the 25 tests performed, namely: the relative pile-cap position, $H_{c} / h$; test duration, $t_{d}$; scour depth measured at the end of the test, $d_{s m}$; equivalent pier diameter, $D_{e}$; and equilibrium scour depth, $d_{s e}$. Each test is named by associating the model number ( 1 to 3 , Table 1 ) and

Table 2. Pile-Cap Positions Tested

\begin{tabular}{lcc}
\hline Situation & Position & $H_{c} / h$ \\
\hline 1 & $\mathrm{~A}$ & 1.700 \\
& $\mathrm{~B}$ & 1.150 \\
& $\mathrm{C}$ & 1.000 \\
& $\mathrm{D}$ & 0.667 \\
2 & $\mathrm{E}$ & 0.333 \\
& $\mathrm{~F}$ & 0.185 \\
& $\mathrm{G}$ & 0.050 \\
& $\mathrm{H}$ & 0.000 \\
3 & $\mathrm{I}$ & $-0.235 /-0.250$ \\
& $\mathrm{~J}$ & -0.500 \\
& $\mathrm{~K}$ & -1.500 \\
\hline
\end{tabular}


Table 3. Experimental Series: Relative Pile-Cap Positions, End Scour Depths, Durations, and Equilibrium Scour Depths

\begin{tabular}{|c|c|c|c|c|c|c|c|c|c|c|c|c|c|c|c|}
\hline \multirow[b]{3}{*}{$\underline{H_{c} / h}$} & \multicolumn{5}{|c|}{ Model 1} & \multicolumn{5}{|c|}{ Model 2} & \multicolumn{5}{|c|}{ Model 3} \\
\hline & & $t_{d}$ & $d_{s m}$ & $D_{e}$ & $d_{s e}$ & & $t_{d}$ & $d_{s m}$ & $D_{e}$ & $d_{s e}$ & & $t_{d}$ & $d_{s m}$ & $D_{e}$ & $d_{s e}$ \\
\hline & Test & (h) & $(\mathrm{mm})$ & $(\mathrm{mm})$ & $(\mathrm{mm})$ & Test & (h) & $(\mathrm{mm})$ & $(\mathrm{mm})$ & $(\mathrm{mm})$ & Test & (h) & $(\mathrm{mm})$ & $(\mathrm{mm})$ & $(\mathrm{mm})$ \\
\hline 1.700 & $1-\mathrm{A}$ & 310 & 114 & 89 & 123 & $2-A$ & 310 & 114 & 89 & 123 & $3-A$ & 310 & 114 & 89 & 123 \\
\hline 1.150 & $1-B$ & 406 & 126 & 98 & 144 & $2-B$ & 406 & 126 & 98 & 144 & $3-B$ & 406 & 126 & 98 & 144 \\
\hline 1.000 & $1-\mathrm{C}$ & 413 & 139 & 115 & 156 & $2-\mathrm{C}$ & 413 & 139 & 115 & 156 & $3-\mathrm{C}$ & 413 & 139 & 115 & 156 \\
\hline 0.667 & 1-D & 311 & 123 & 120 & 161 & $2-\mathrm{D}$ & 675 & 141 & 127 & 175 & 3-D & 412 & 145 & 136 & 185 \\
\hline 0.333 & $1-E$ & 431 & 116 & 125 & 159 & $2-E$ & 646 & 141 & 138 & 177 & $3-E$ & 599 & 133 & 157 & 192 \\
\hline 0.185 & $1-\mathrm{F}$ & 577 & 145 & 126 & 168 & $2-\mathrm{F}$ & - & - & - & - & $3-\mathrm{F}$ & - & - & - & - \\
\hline 0.050 & $1-\mathrm{G}$ & 671 & 95 & 121 & 118 & $2-\mathrm{G}$ & 351 & 127 & 139 & 175 & $3-G$ & 593 & 169 & 162 & 189 \\
\hline 0.000 & $1-\mathrm{H}$ & 647 & 79 & 120 & 112 & $2-\mathrm{H}$ & 594 & 185 & 138 & 225 & $3-\mathrm{H}$ & 671 & 200 & 162 & 245 \\
\hline-0.235 & $1-\mathrm{I}$ & 1,126 & 89 & 115 & 103 & $2-\mathrm{I}$ & 576 & 121 & 139 & 162 & - & - & - & - & - \\
\hline-0.250 & - & - & - & - & - & - & - & - & - & - & $3-\mathrm{I}$ & 527 & 190 & 164 & 212 \\
\hline-0.500 & $1-\mathrm{J}$ & 595 & 115 & 111 & 148 & 2-J & 600 & 126 & 139 & 184 & $3-\mathrm{J}$ & 1,126 & 199 & 167 & 228 \\
\hline-1.500 & $1-\mathrm{K}$ & 597 & 155 & 110 & 178 & $2-K$ & 696 & 166 & 140 & 218 & $3-K$ & 648 & 193 & 170 & 240 \\
\hline
\end{tabular}

Note: Tests 1-A, 2-A, and 3-A (column out of water) correspond to the same test; the same applies to tests 1-B, 2-B, and 3-B and tests 1-C, 2-C, and 3-C.

the pile-cap position reference (Table 2) (e.g., 3-E applies to the test with Model 3 in Position E), as shown in Table 3.

According to Chiew and Melville (1987), the flow contraction effect is negligible when $D_{p c} / B \leq 0.10$ ( $B$ the flume width and $D_{p c}$ the pile-cap width). In line with Yalin (1971), the wall effect is also negligible when $B / h>5$. The chosen relations $D_{p c} / B=$ 0.10 and $B / h=10$ could guarantee the absence of contraction and wall effects.

Following the early work of Chabert and Engeldinger (1956) and as stated in Ettema (1980), it can be assumed that the equilibrium stage in the scour evolution is attained asymptotically. Hence, in order to estimate the equilibrium scour depth, $d_{\text {se }}$, the recorded experimental scour depth values were extrapolated to time infinite by means of the following equation:

$$
d_{s}=d_{s e}\left[1-e^{-a\left(\frac{U t}{D_{e}}\right)^{b}}\right]
$$

where $d_{s}=$ the scour depth at time $t$; and $a$ and $b=$ parameters obtained by regression analysis. Eq. (1) is a modification of the Franzetti et al. (1982) equation, in which the single cylindrical pier diameter of the original expression, $D_{p}$, was replaced by a parameter $D_{e}$ representative of the equivalent diameter for the complex pier. $D_{e}$ was calculated with the equations suggested by Coleman (2005). Those values and the equilibrium scour-depth values are also included in Table 3.

\section{Temporal Evolution of the Scour Depth}

Recent studies (e.g., Ataie-Ashtiani et al. 2010; Moreno et al. 2012; Ferraro et al. 2013) show that the scour depth evolution in complex piers follows different stages in comparison with single piers. That is associated with the progressive physical presence in the scour hole evolution of one, two, or three structural components of the complex pier. The duration and trend of the different stages depend on the relative column width, $D_{c} / D_{p c}$; the relative pile-cap thickness, $T / h$; the relative pile-cap position, $H_{c} / h$; and the complex pier components shapes.

In Fig. 2, the results of the temporal evolution of maximum scour depth $\left(d_{s}\right)$ are plotted against $t$ for each model in three different pile-cap positions, each corresponding to one of the three situations analyzed. For each position, the increment in the scourdepth values (temporal evolution) is directly associated with the increment in the column width, this fact being more evident for Situation 3 (when the column component is present in the scour cavity throughout all the scour development process). The complete time records of the scour depth are available at https://drive.google .com/file/d/0B7JmeEhYWblkU1htTjRreDRxQUk.

In Situation $1(\mathrm{~S} 1)$, corresponding to positions A $\left(H_{c} / h=1.70\right)$ to $\mathrm{D}\left(H_{c} / h=0.67\right)$, only one stage of the scour process was observed [Fig. 2(a)]. That process initiates in front of each of the upstream piles, with individual holes, until they merge into one single scour hole. The scour depth evolution in this situation is similar to that observed in pile groups (e.g., Lança et al. 2013).

In Situation $2(\mathrm{~S} 2)$, corresponding to positions $\mathrm{E}\left(H_{c} / h=0.33\right)$ to $\mathrm{H}\left(H_{c} / h=0.0\right)$, when the pile cap is only slightly buried in the bed (i.e., Position E), three stages of the scour process were identified [Fig. 2(b)]: initially (Stage A), in which the process develops in front of the pile cap (S2-A); next (Stage B), it progresses below the pile cap (S2-B) and finally (Stage C) it continues underneath the pile cap, in front of the upstream piles (S2-C). These findings are in agreement with those of Ferraro et al. (2013). However, when the pile cap is almost buried at the initiation of the scour process, i.e., the top surface of the pile cap is near or flushes the initial bed level, the last two stages may not occur depending on $D_{c} / D_{p c}$ ratio, as was the case for Positions $G$ and $H$ (https://drive .google.com/file/d/0B7JmeEhYWblkU1htTjRreDRxQUk). In fact, in line with Melville and Raudkivi (1996) and Ataie-Ashtiani et al. (2010), when $H_{c} \approx 0$, the front and side pile-cap extension lengths do cause not only a delay in the beginning of the scour process but also a slow initial scour rate. For these cases, when $D_{c} / D_{p c}$ ratio is small (e.g., Model $1, D_{c} / D_{p c}=0.55$ ), the scour depth evolution (tests 1-G and 1-H, see https://drive.google.com/file/d/ 0B7JmeEhYWblkU1htTjRreDRxQUk) follows a similar behavior to the one observed in experiments of single piers with collar countermeasure (e.g., Mashahir et al. 2004; Alabi 2006), in which a reduction of the downflow in front of the column and a reduction of the horseshoe vortices were detected.

In Situation $3(\mathrm{~S} 3)$, corresponding to positions I $\left(H_{c} / h \approx\right.$ $-0.24 /-0.25)$ to $\mathrm{K}\left(H_{c} / h=-1.50\right)$, when the pile cap is completely buried at the beginning of the scour process, three stages of the scour process could be typically observed [Fig. 2(c)]: initially, scouring develops in front of the column until the scour hole partly uncovers the top of the pile cap (S3-A); that period is followed by a stage (S3-B) when the scour depth does not evolve during a (more or less significant, depending on the model) lapse of time and the maximum scour depth is equal to the distance from the initial bed level to the top of the pile cap; on the following stage, the scour process continues in front of the pile cap (S3-C). This observation is in line with the findings of Melville and Raudkivi (1996), 

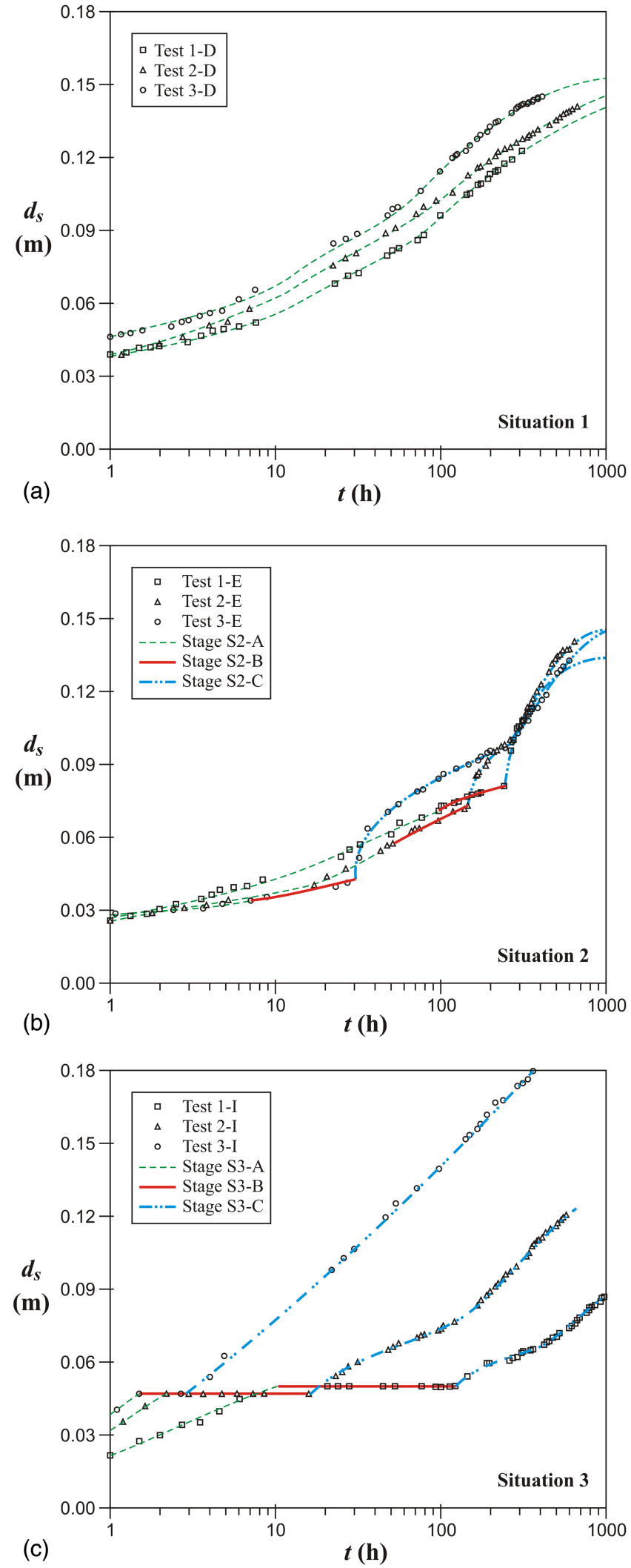

Fig. 2. Temporal evolution of the scour depth on (a) Situation 1; (b) Situation 2; (c) Situation 3 (Stages A, B, and C are represented by lines with different patterns)

Ataie-Ashtiani et al. (2010), Lu et al. (2011), and Ferraro et al. (2013). In accordance with Melville and Raudkivi (1996), when $D_{c} / D_{p c}$ is close to 1 (e.g., Model 3) the duration of the intermediate stage (S3-B) is short and the scour depth evolution resembles to the one corresponding to single piers, as shown in Fig. 2(c) for Test 3-I. It also comes clear that the duration of the two last stages (B and C) is highly sensitive to $H_{c} / h$ and $D_{c} / D_{p c}$. In accordance with the observations by Melville and Chiew (1999) for single piers, the scouring rate depends on the flow intensity, $U / U_{c}$. This ratio shall also influence, and significantly, the time duration of Stage B. In fact, that time duration for $U / U_{c} \approx 1.0$ shall be about the double than one obtained for the present study $\left(U / U_{c} \approx 0.80\right)$. Finally, in Position K, characterized by the top of the pile cap remaining below the base of the scour hole at the end of the scour process, only the first scouring stage was observed, as expected (see https://drive .google.com/file/d/0B7JmeEhYWblkU1htTjRreDRxQUk).

\section{Criterion to Stop the Laboratory Experiments}

Some authors (e.g., Coleman 2005; Ataie-Ashtiani et al. 2010; Ferraro et al. 2013) use the same criterion proposed by Melville and Chiew (1999) for experimental tests with single piers as a criterion to stop laboratory tests on complex piers (assuming that the tests have reached the equilibrium scour stage): $\Delta d_{s}<0.05 D_{e}$, $\Delta d_{s}=$ increment of scour depth in $24 \mathrm{~h}$. Applying this criterion to the 25 tests of the present study, the time duration to reach the equilibrium condition should be on average 98, 86, and $96 \mathrm{~h}$ for Situations 1, 2 and 3 respectively. Nevertheless, those time durations would have been smaller than those required to obtain the different scouring phases detected (namely, Stages B and C in Situations 2 and 3). Comparing the values of scour depth measured at time defined according to Melville and Chiew (1999), $d_{\mathrm{smMC}}$, with the ones measured at the end of the process (Table 3 ), the corresponding ratio $d_{\mathrm{smMC}} / d_{s m} \approx[0.80,0.63,0.70]$ is obtained for Situations 1 to 3 respectively. Tests $1-\mathrm{G}$ and $1-\mathrm{H}$ were excluded from this analysis due to the corresponding low initial scour rate values, mentioned in the previous section.

It is assumed herein that the expressions developed by Sheppard et al. (2011), taking into account the findings of Melville and Chiew (1999), for estimating the time to reach $90 \%$ of $d_{s e}$ are adequate to estimate test durations at complex piers. In accordance, the test duration, $t_{\mathrm{dMS}}$, was evaluated by

$t_{\mathrm{dMS}}($ days $)= \begin{cases}200 \frac{D_{e}}{U}\left(\frac{U}{U_{c}}-0.4\right) e^{-1.83 \frac{U}{U_{c}}} & \text { for } \frac{h}{D_{e}}>6 \\ 127.8 \frac{D_{e}}{U}\left(\frac{U}{U_{c}}-0.4\right)\left(\frac{h}{D_{e}}\right)^{0.25} e^{-1.83 \frac{U}{U_{c}}} & \text { for } \frac{h}{D_{e}} \leq 6\end{cases}$

Eq. (2) is valid for $U / U_{c}>0.4$. In this equation, the pier width of the original expression (Sheppard et al. 2011) was replaced by an equivalent diameter $D_{e}$ of the complex pier $\left[D_{e}\right.$ can be calculated with the expressions suggested by Coleman (2005)]. The application to the tests of this study enabled to obtain the scour depth $\left(d_{s m 2}\right)$ measured at the time duration defined $\left(240 h<t_{\mathrm{dMS}}<390 h\right)$ according to Eq. (2) and the corresponding ratio $d_{s m 2} / d_{s m} \approx$ $[0.95,0.76,0.85]$ for Situations 1 to 3 respectively. These results confirm that Eq. (2) is a good approximation to estimate a priori the time duration of the scour tests to be performed.

\section{Influence of Relative Column Width and Pile-Cap Elevation on Equilibrium Scour Depth}

The study tests were performed for different relative pile-cap positions, $H_{c} / h$, and different values of the ratio of column width to pile-cap width, $D_{c} / D_{p c}$. In order of that, four recognized parameters that influence the equilibrium scour depth, $d_{s e}$, could change (1) the width of the column; (2) the pile-cap front and side overhang length (distance from the edge of the column to the edge of the 


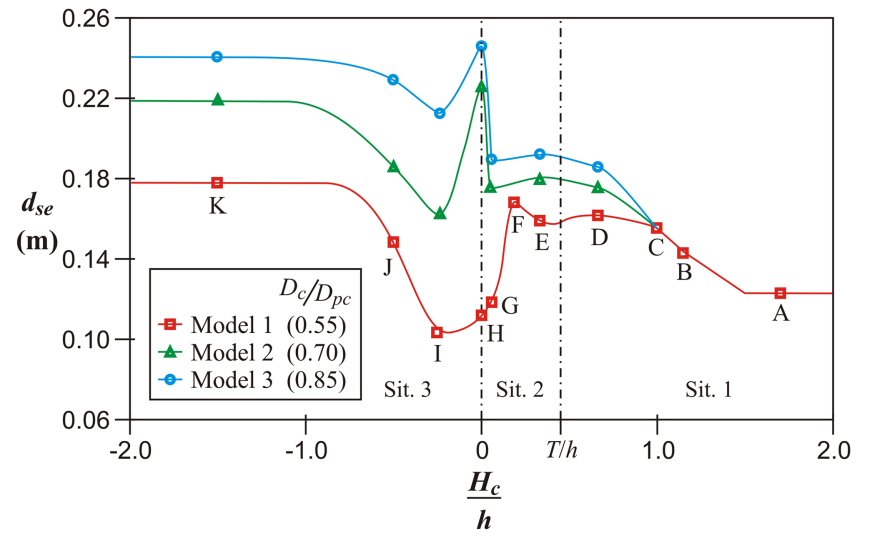

Fig. 3. Equilibrium scour depth as function of relative pile-cap position for different models

pile cap); (3) the sediment coarseness ratio (expressed by $D_{e} / d_{50}$ ); and (4) the flow shallowness ratio (expressed by $h / D_{e}$ ). Nevertheless, it can be considered that the effects of sediment coarseness and flow shallowness are practically the same for all the three models and the corresponding pile-cap positions. These two effects were calculated by the equations suggested by Sheppard et al. (2014) using the $D_{e}$ values of Table 3. Taking that into account, in this study the $d_{s e}$ variations in the three models are associated only with the ratio $D_{c} / D_{p c}$ and the pile-cap overhang length.

Fig. 3 shows the equilibrium scour depth, $d_{s e}$, resulting from data extrapolation based on Eq. (1), as a function of the relative pile-cap position, $H_{c} / h$, for the three models studied. The figure includes two vertical lines at $H_{c} / h=0$ and $H_{c} / h=T / h$ to delimit the regions associated to the three initial situations analyzed: pile cap above the bed (Situation $1, H_{c} / h>T / h$ ), pile cap partially buried (Situation 2, $0 \leq H_{c} / h \leq T / h$ ) and pile cap completely buried (Situation 3, $H_{c} / h<0$ ). In general, the $d_{s e}$ variation with $H_{c} / h$ is similar for the three models. The increment in $d_{s e}$ values associated to each model is related to the increment of the column width and also to the corresponding reduction of the pile-cap front and side extension lengths, i.e., an increase in $D_{c} / D_{p c}$ ratio.

For Situation 1, when compared to Position A (column and pile cap out of the water), an increase in $d_{\text {se }}$ with increasing submergence of the pile cap occurs for Position B (partial submergence) and for Position $\mathrm{C}$ (full submergence), as shown in Fig. 3. That increase is justified by the frontal area exposed to the flow due to the pile cap being larger than the one corresponding to the upstream piles (Position A). For these two positions (B and C), $d_{s e}$ is identical for all models as the pile group and the pile cap have the same geometrical definition and the column is still out of water. The increase of $d_{s e}$ in Position D (all three elements exposed to the flow) relative to Position $\mathrm{C}$ is different for the three models, with $d_{s e}$ clearly increasing with the column width size (and so, with the area exposed to the flow).

In Situation 2, when the pile cap is only slightly buried in the bed (Position E), the $d_{s e}$ values and comparative differences between the three models are similar to that observed in Position $\mathrm{D}$, as shown in Fig. 3. Nevertheless, when the pile cap is almost buried in the bed (Position G), although a similar trend does occur for the two wider-column models (Models 2 and 3, $D_{c} / D_{p c} \geq$ 0.70) when compared to the values of $d_{s e}$ at Position $E$ for the same models, a sharp decrease in $d_{s e}$ for Model $1\left(D_{c} / D_{p c}=0.55\right)$ is observed in a similar comparison. That different behavior is mostly associated with the pile-cap overhang dimension's influence on the flow structure around the column above the pile cap: for large column-to-pile-cap width ratios $\left(D_{c} / D_{p c} \geq 0.70\right)$, the downflow along the upstream face of the column is only negligibly affected by the reduced pile-cap overhang dimension on its way downwards the upstream face of the pile cap when the scour hole is developed, whereas for smaller column-to-pile-cap width ratios $\left(D_{c} / D_{p c}=\right.$ $0.55)$ the pile-cap overhang length is enough to deflect the downflow along the column and to reduce the strength of the horseshoe vortex in order to influence and disturb the scouring process. In addition to that, and specifically for this last case, it should be mentioned that (1) the pile group stops contributing to the scour process at Position $\mathrm{G}$, as the scour cavity no longer exposes completely the front face of the pile cap; and (2) the interaction of the bottom flow boundary layer with the deflected downflow of the column affects also the development of both the downflow and the horseshoe vortex system around the pile cap. Quite close to Position G, Position $\mathrm{H}$ corresponds to the lower limit of Situation 2, with the pile cap initially flush with the bed. The referred overhanging enhanced protecting effect, translated into a delay in the beginning of the scour process and on a reduction of the initial scour rate, may justify the slight decrease (and a minimum, for Situation 2) on $d_{s e}$ for Model 1 from Position $\mathrm{G}$ to Position $\mathrm{H}$. The similar analysis for Models 2 and $3\left(D_{c} / D_{p c} \geq 0.70\right)$ does show again a very different behavior comparatively to Model $1\left(D_{c} / D_{p c}=0.55\right)$, this time by a very sharp increase in $d_{s e}$ in Position $\mathrm{H}$ compared to Position G. In fact, for these two cases a maximum of $d_{s e}$ is achieved for Position H. That apparently can be explained by (1) the disappearance of the pile-cap protrusion from the bed level and, so, of any obstruction from the bed flow boundary layer to the downflow at the beginning of the scour process; and (2) the contribution of a larger obstruction area (i.e., corresponding to the entire pile-cap thickness) exposed inside the developed scour hole, therefore leading to an increase of horseshoe vortex intensity and the corresponding scour rate. Concerning Model 1, the described specific comparative behavior for Positions $\mathrm{E}-\mathrm{H}$ enabled prediction of the occurrence of a maximum value of $d_{s e}$ on an intermediate position, corresponding (or close) to Position F (Fig. 3).

In accordance with Ataie-Ashtiani et al. (2010) and Ferraro et al. (2013), the maximum $d_{\text {se }}$ value always occurs in Situation 2, when the three components of the complex pier are progressively exposed to the flow during the scour process, the scouring development being dominated by the pile cap (larger-width element of the pier). The specific position at which this maximum occurs depends on $D_{c} / D_{p c}$ ratio (Fig. 3): in Models 2 and 3, the maximum $d_{s e}$ occurred at Position $\mathrm{H}\left(H_{c} / h=0.0\right)$ whereas in Model 1 , it occurred at Position F $\left(H_{c} / h=0.18\right)$. For Model 1 at Position F, the maximum $d_{s e}$ may be explained by (1) the pile-cap protrusion above the referred effects of obstruction of the flow boundary layer at the beginning of the scour process does contribute, in this case, to the development of both the downflow and the horseshoe vortex system around the pile cap; and (2) the contribution of the upstream piles on the scour process, a condition that does not occur in Model 1 when the top surface of the pile cap is near or flushes the initial bed level (Situation 2). The first reason was also referred by Parola et al. (1996) in experiments on piers with rectangular foundations.

The $d_{s e}$ behavior as function of $H_{c} / h$ in Situation 3 (Fig. 3) was similar to the one obtained by Melville and Raudkivi (1996) and Umeda et al. (2010) for tests with cylindrical piers founded on cylindrical caissons. The $d_{s e}$ reduction at Position I in comparison to $d_{s e}$ values at Position $\mathrm{H}$ is due to the effect of the overhanging of the pile cap from the column, made active after the top of this element is reached on the scour process, by that interfering on the scour cavity development process (by physical obstruction on the cavity and by weakening the flow structure induced by the column while confined by the above-adjacent sand bed). In agreement with 
Table 4. Experimental Models: Characteristic Relations of Flow, Model Geometry, Bed Granulometry Parameters, and Duration of the Tests

\begin{tabular}{|c|c|c|c|c|c|c|c|c|c|c|c|c|c|}
\hline Model & $U / U_{c}$ & $B / h$ & $D_{p c} / B$ & $D_{c} / D_{p c}$ & $f_{l} / f_{t}$ & $T / h$ & $T / d_{s c}$ & $h / D_{e *}$ & $D_{e *} / d_{50}$ & $d_{50}(\mathrm{~mm})$ & Colum shape & Pile cap shape & $t_{d}$ (day) \\
\hline $\mathrm{Co} 1$ & 0.75 & 2.5 & 0.08 & 0.25 & 0.00 & 0.10 & 0.78 & 9.92 & 72 & 0.84 & $\mathrm{R}$ & $\mathrm{R}$ & NS \\
\hline $\mathrm{Co} 2$ & 0.85 & 2.5 & 0.08 & 0.25 & 1.11 & 0.10 & 0.78 & 9.92 & 72 & 0.84 & $\mathrm{R}$ & $\mathrm{R}$ & NS \\
\hline $\mathrm{Co} 3$ & 0.83 & 4.6 & 0.13 & 0.53 & 0.89 & 0.24 & 0.37 & 1.97 & 141 & 0.84 & $\mathrm{R}$ & $\mathrm{R}$ & NS \\
\hline AA1 & $0.72-0.85$ & $\approx 4.0$ & 0.15 & 0.24 & 0.44 & $\approx 0.22$ & 0.76 & $\approx 3.5$ & 70 & 0.60 & $\mathrm{R}$ & $\mathrm{R}$ & $0.4-3.1$ \\
\hline AA2 & $0.74-0.80$ & $\approx 4.0$ & 0.15 & 0.47 & 0.96 & $\approx 0.28$ & 0.70 & $\approx 3.0$ & 83 & 0.60 & $\mathrm{R}$ & $\mathrm{R}$ & $0.4-2.1$ \\
\hline GC & 0.92 & 7.0 & 0.21 & 0.34 & 1.00 & 0.50 & 0.45 & 0.91 & 92 & 0.83 & $\mathrm{C}$ & $\mathrm{C}$ & $4.8-18.1$ \\
\hline $\mathrm{Fe}$ & 0.92 & 7.0 & 0.21 & 0.33 & 1.00 & 0.50 & 0.50 & 0.93 & 90 & 0.83 & RNR & RNR & $8.3-37.0$ \\
\hline PS1 & 0.80 & 10.0 & 0.10 & 0.55 & 1.00 & 0.45 & 0.58 & 1.58 & 148 & 0.86 & RNR & RNR & $12.9-46.9$ \\
\hline PS2 & 0.80 & 10.0 & 0.10 & 0.70 & 1.00 & 0.45 & 0.54 & 1.41 & 165 & 0.86 & RNR & RNR & $12.9-29.0$ \\
\hline PS3 & 0.80 & 10.0 & 0.10 & 0.85 & 1.00 & 0.45 & 0.47 & 1.22 & 190 & 0.86 & RNR & RNR & $12.9-46.9$ \\
\hline
\end{tabular}

Note: Co = Coleman (2005); AA = Ataie-Ashtiani et al. (2010); GC = Grimaldi and Cardoso (2010); Fe = Ferraro et al. (2013); PS = present study; $D_{e *}=$ maximum equivalent diameter (calculated according to Coleman 2005); $\mathrm{R}=$ rectangular; $\mathrm{C}=$ circular; $\mathrm{RNR}=$ round nose rectangular; NS $=$ not specified.

Melville and Raudkivi (1996), the increase on $d_{s e}$ values on decreasing $H_{c} / h$ ratio, from Position I to Positions $\mathrm{J}$ and $\mathrm{K}$, is due to the scour depth being controlled by the position of the top of the pile cap in the scour cavity. The rate of increase depends on the $D_{c} / D_{p c}$ ratio, being higher for smaller values of $D_{c} / D_{p c}$.

\section{Discussion of Results}

In order to evaluate the influence of the relative column width and of the pile-cap position on equilibrium scour depth, experimental data obtained by (a) (Coleman 2005; Sheppard and Renna 2010); (b) Ataie-Ashtiani et al. (2010); (c) Grimaldi and Cardoso (2010); and (d) Ferraro et al. (2013) were considered in addition to the data from the present study. The evaluation was performed only for Situations 2 and 3 (where the pile cap is, respectively, partially buried and completely buried in the bed at the beginning of the scour process), since the effect of the relative column width is most relevant for those two situations, as justified in the previous section and displayed in Fig. 3 for data from the present study. In both situations, the analysis was based on the $d_{s e}$ variation as function of $H_{c}$. For Situation 2, the position at which the maximum $d_{s e}$ occurs was also evaluated.

Table 4 summarizes the characteristic relations involving flow conditions, complex pier geometries, and bed granulometries of seven complex pier models reported in literature, as well as of the three models considered in the present study. Table 4 includes also the duration of the reported tests. In all the 10 experimental models, coarse sand ( $d_{50} \geq 0.6 \mathrm{~mm}$ ) was used, accounted for being insusceptible to the formation of ripples in the approach flow reach. The experimental range of all the models covered the three situations studied (by considering different values of $H_{c}$ ), with exception of the Model Co2 for which the Situation 3 was not considered.

Given that the scour-depth data reported by each of the mentioned authors was not extrapolated-and most of the scour-depth records were not available, not allowing the required extrapolation of $d_{s e}$ values - the comparative analysis of the literature and the present study results was performed and will be described by taking into account the scour-depth values measured at the end of the experiments, $d_{s m}$. Similar behavior could be identified in the equilibrium scour-depth variation as a function of $H_{c} / h$ obtained by considering the extrapolated values and the measured values for the models where the time series are available (Models of Fe, GC, and of the present study). The corresponding extrapolated values did show a shift of 10-20\% (depending on the models) to the measured values. Analyzing the full range of $d_{s m}$ variation as a function of $H_{c} / h$ for all complex pier models (https://drive.google.com/file/ d/OB7JmeEhYWblkU1htTjRreDRxQUk), it could be concluded that the scour-depth variation is analogous between the seven reported models and the three models of the present study. In the seven reported models the maximum scour depth was also observed in Situation 2, as expected. In accordance, the pile-cap position at which the maximum scour depth occurs can be estimated from either the measured or the extrapolated series.

As the experimental tests were not performed under the same conditions (Table 4), the measured scour-depth values were adjusted taking into account the influence of flow shallowness, $h / D_{e}$; of flow intensity, $U / U_{c}$; and of sediment coarseness, $D_{e} / d_{50}$. The adjustment process was accomplished through Sheppard/Melville equation (Sheppard et al. 2014), in which $D_{e}$ was calculated according to Coleman (2005).

For a comparative analysis of the 10 complex pier models under Situation 2 (i.e., $\left.0 \leq H_{c} \leq T\right), d_{s m}$ and $H_{c}$ values were normalized, respectively, by $D_{p c}$ (as the pile cap is the main component to contribute to the scour process in that situation) and by $T$ (parameter that defines the upper limit of $H_{c}$ for that situation). The adjusted values of $d_{s m} / D_{p c}$ are plotted against $H_{c} / T$ in Fig. 4. Fig. 4(a) corresponds to the experimental models with rectangular pile caps whereas Fig. 4(b) relates to the experimental models with circular and rectangular round-nose pile caps. The analysis highlights that

1. In general, the relative difference in $d_{s m}$ values may be associated with the effect of the relative column width, $D_{c} / D_{p c}$, the effect of the pile-cap extensions symmetry, $f_{l} / f_{t}$; the pile-cap shape; the relative pile-cap thickness; $T / h$, and the test duration, $t_{d}$.

2. In line with the findings of Coleman (2005), the fact that over the full $H_{c} / T$ range all the $d_{s m} / D_{p c}$ values of Model Co1 are higher than the ones of Model $\mathrm{Co} 2$, as shown in Fig. 4(a), is due to the fact that, in the first case (where $f_{l} / f_{t}=0$ ), the downflow in front of the column is not affected by the upstream pile-cap extension.

3. Models GC and Fe were used to evaluate the effect of shape on $d_{s m}$, since this was the main changing parameter between both models. The results suggest that similar columns and pile-cap configurations sets with circular or round-nose rectangular shapes are leading to identical scour-depth values, as shown in Fig. 4(b).

The assessment of the critical relative pile-cap position at which the maximum scour depth can occur, $\left(H_{c} / T\right)_{\max }$, is important in terms of complex pier design. The experimental fitting curves presented for the different models on Figs. 4(a and b) do enable the corresponding values of $\left(H_{c} / T\right)_{\max }$ to be obtained, included in Table 5. It is clear that $\left(H_{c} / T\right)_{\max }$ decreases within the range 0.83 to 0.28 when $D_{c} / D_{p c} \leq 0.55$ and is null $(=0)$ when $D_{c} / D_{p c} \geq 0.70$. It can be assumed (by extrapolation of the trend 

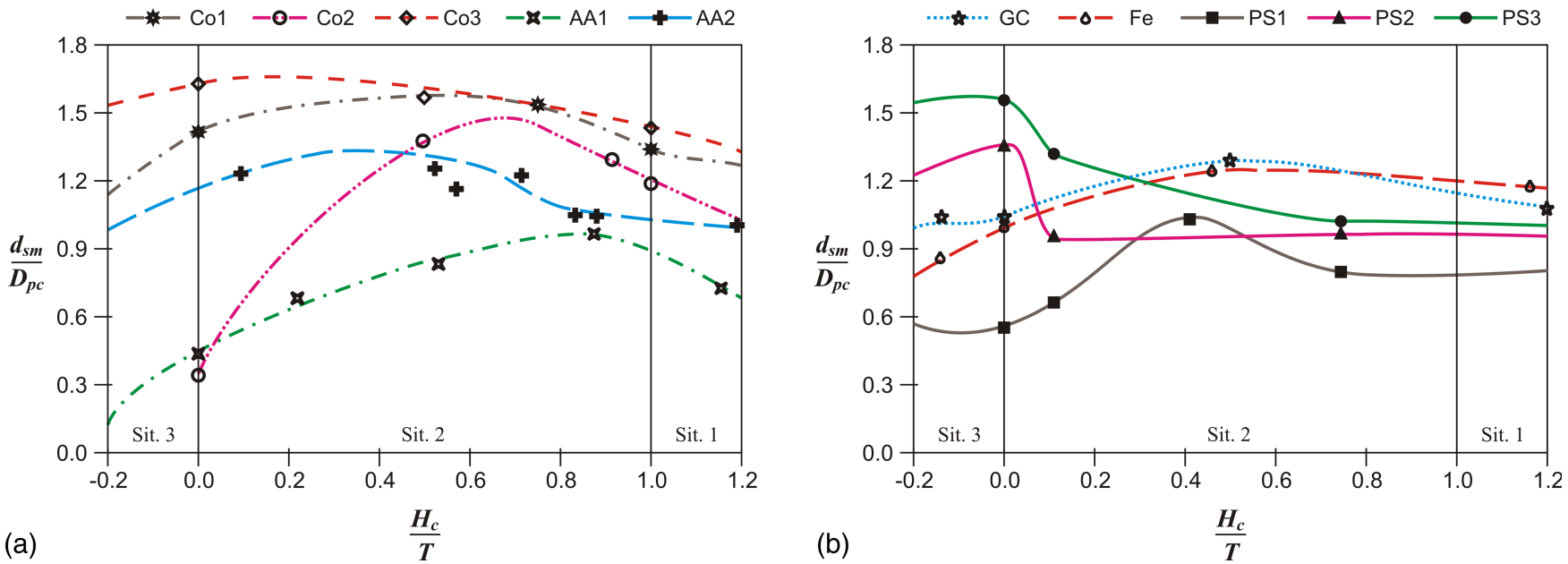

Fig. 4. $d_{s m} / D_{p c}$ as function of $H_{c} / T$ for Situation 2: (a) rectangular pile-cap shape; (b) circular and rectangular round-nose pile-cap shapes

Table 5. Values of the Critical Pile-Cap Position at Which the Maximum Scour Depth is Obtained as Function of Relative Column Width

\begin{tabular}{lcccccccccc}
\hline Parameter & AA1 & Co1 & Co2 & Fe & GC & AA2 & Co3 & PS1 & PS2 & PS3 \\
\hline$D_{c} / D_{p c}$ & 0.24 & 0.25 & 0.25 & 0.33 & 0.34 & 0.47 & 0.53 & 0.55 & 0.70 & 0.85 \\
$\left(H_{c} / T\right)_{\max }$ & 0.83 & 0.75 & 0.66 & 0.62 & 0.58 & 0.47 & 0.28 & 0.41 & 0.00 & 0.00 \\
\hline
\end{tabular}

line associated to $\left(H_{c} / T\right)_{\max }$ values in the range $\left.D_{c} / D_{p c} \leq 0.55\right)$ that the ratio $D_{c} / D_{p c}=0.65$ is the minimum value for which the maximum scour depth occurs at position $H_{c}=0$.

The analysis of results reveals that the pile-cap position is directly influenced by $D_{c} / D_{p c}$. Nevertheless, that position may also be influenced by the flow shallowness, $h / D_{p c}$, and by the symmetry of the pile-cap extensions, $f_{l} / f_{t}$. The following regression equation takes the full parameters' dependence in due account:

$\left(\frac{H_{c}}{T}\right)_{\max }=\left\{\begin{array}{cc}0 & \text { for } \frac{D_{c}}{D_{p c}}>0.65 \\ \frac{\left[0.9+0.1\left(\frac{f_{l}}{f_{t}}\right)^{0.4}\right]\left[0.84-3.1\left(\frac{D_{c}}{D_{p c}}\right)^{3.1}\right]}{K_{s p c}\left\{\tanh \left[\frac{h}{D_{p c}}\left(\frac{D_{c}}{D_{p c}}\right)^{-0.5}\right]\right\}^{0.2}} & \text { for } 0.15 \leq \frac{D_{c}}{D_{p c}} \leq 0.65\end{array}\right.$ where $K_{\mathrm{spc}}=$ pile-cap shape factor (1.04 for rectangular shape and 1.0 for circular or round-nose rectangular shapes). In the range $0.15 \leq D_{c} / D_{p c} \leq 0.65$, the determination coefficient is $r^{2}=0.76$ and the root mean square error is RMSE $=0.12$. The lower limit of the range was fixed at 0.15 , as this value corresponds to a complex pier configuration with $f_{t} \approx 3 D_{c}$ (with $f_{l} / f_{t}=1$ ), a value that may be considered as a maximum practical ratio in engineering terms.

For a comparative analysis of the complex pier models under Situation 3 (i.e., $H_{c}<0$ ), the $d_{s m}$ and $H_{c}$ values were both normalized by $d_{s c}$ (depth of local scour for a uniform single pier with the same geometrical definition of the complex pier column). The variable $d_{s c}$ was selected as the normalization factor since the column is the main component to contribute to the scour process in this situation. Fig. 5 displays the effect of $D_{c} / D_{p c}$ and of the column/pile-cap shapes on $d_{s m} / d_{s c}$ as function of $H_{c} / d_{s c}$. Similarly to what was mentioned for Situation 2, the CG (circular column/ pile-cap shapes) and $\mathrm{Fe}$ (round-nose rectangular column/pile-cap shapes) models do show an analogous scour depth variation, as shown in Fig. 5(a), where these results are compared with the ones obtained by Melville and Raudkivi (1996) for a cylindrical columncaisson model with $D_{c} / D_{p c}=0.37$ (represented by MR). The apparent reduction of $d_{s m}$ in Models CG and Fe compared to
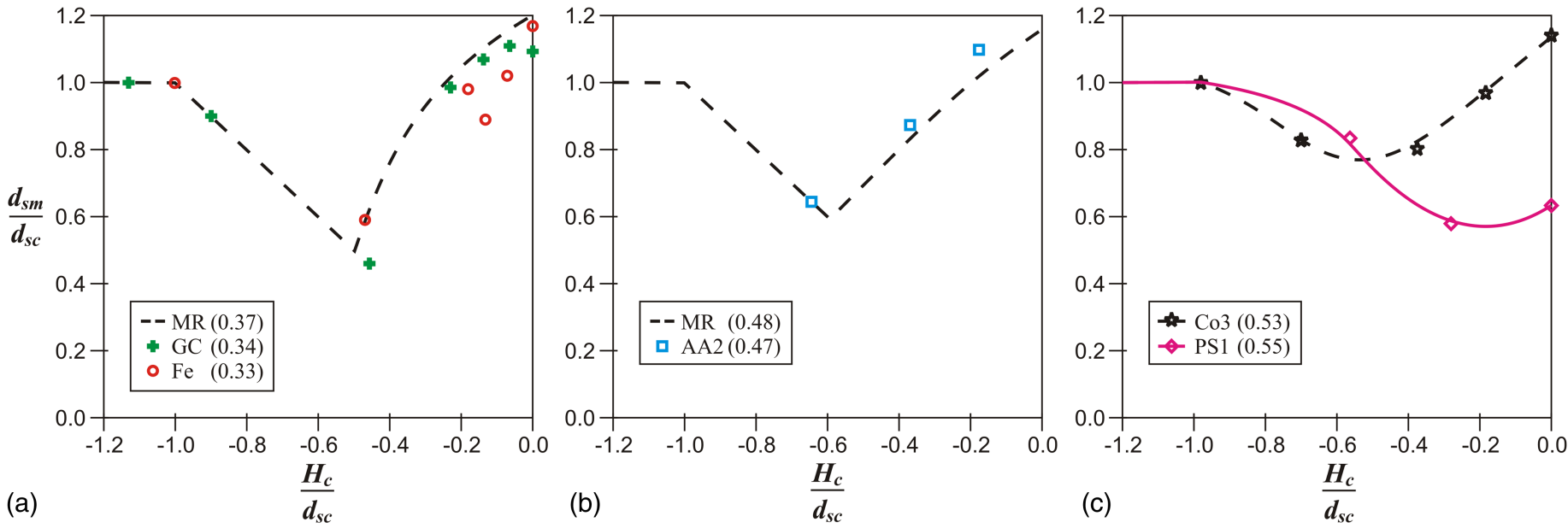

Fig. 5. Effect of the pile-cap shape and $D_{c} / D_{p c}$ on $d_{s m} / d_{s c}$ as function of $H_{c} / d_{s c}$ for Situation 3 
Model MR is due to the smaller scour rate that occurs for $-0.3<H_{c} / d_{s c}<0$, where the scour process is developing below the pile cap. This may be due to discontinuity between the pile cap's front and the scour hole's bottom, that leads to a reduction of the strength of the downflow and horseshoe vortices for Models $\mathrm{CG}$ and Fe. Fig. 5(b) shows the comparison of $d_{s m} / d_{s c}$ for a complex pier with rectangular column/pile-cap shapes (Model AA2) and a cylindrical column-caisson model (Model MR for $D_{c} / D_{p c}=0.48$ ). The increment on $d_{s m}$ values of Model AA2 relative to Model MR, approximately $8-10 \%$ on average, may be associated with the pile-cap shape, since results in rectangular piers reflect higher magnitudes of the flow structure (e.g., downflow, horseshoe vortex, vortices, and turbulence intensity) when compared to circular piers, as referred by Dey and Raikar (2007). Fig. 5(c) displays the comparison of Models Co3 (rectangular column/pile-cap shapes) and PS1 (round-nose rectangular column/ pile-cap shapes), where a relevant increase of $d_{s m}$ values is observed in the Model Co3 compared to Model PS1 for the range $-0.5<H_{c} / d_{s c}<0$. This increment can be associated mainly to geometry definitions of Model Co3, namely: the relatively thinner pile cap $\left(T / d_{s c} \approx 0.37\right)$; the asymmetry of the pile-cap extension lengths $\left(f_{l} / f_{t}=0.89\right)$ and the rectangular shape of both the column and pile cap.

\section{Conclusions}

From the previous discussion, the following important conclusions can be drawn:

1. The temporal evolution of scour depth and the corresponding $d_{\text {se }}$ at complex piers is generally influenced by the relative pile-cap position $\left(H_{c} / h\right)$, by the relative column width (expressed by $D_{c} / D_{p c}$ and $\left.f_{l} / f_{t}\right)$, by the relative pile-cap thickness $(T / h)$, and by the shape of the complex pier components (i.e., column, pile cap, and piles). The different stages in the scour-depth evolution are associated with the number of structural elements of the complex pier that are exposed to the flow inside the scour hole developed along the scouring process.

2. The criterion established to stop the tests by Melville and Chiew (1999) for single piers, also commonly used in complex piers, was evaluated. This criterion seems to no longer have such a good performance when more than one element of the complex pier is exposed to the flow in the scour hole. Eq. (2), based on Sheppard et al. (2011), can be used to estimate the time recommended to stop the tests with complex piers.

3. For all the 10 complex pier models analyzed, the maximum scour-depth value was observed in Situation 2, where the pile cap is partially buried in the bed $\left(0 \leq H_{c} \leq T\right)$. For the lower relative column-width values, i.e., $D_{c} / D_{p c}<0.6$, it could be concluded that the pile-cap overhang from the column face plays the role of an obstruction to the downflow adjacent to the column, reducing the vortex system and hence the scour depth. This reduction is most evident in cases when $H_{c} \approx 0$, for which the flow behaviour is similar to collars in single piers. For larger relative column-width values, i.e., $D_{c} /$ $D_{p c} \geq 0.6$, the influence of the pile-cap overhang is negligible. For practical applications, the critical relative pile-cap position at which the maximum scour depth is achieved can be obtained through Eq. (3).

\section{Acknowledgments}

The authors wish to acknowledge the joint financial support of the Portuguese Foundation for Science and Technology through the research project PTDC/ECM/101353/2008 and the doctoral grant SFRH/BD/76396/2011. The experimental work was carried out at the Hydraulics and Environment Department, National Laboratory for Civil Engineering (LNEC), Lisbon, Portugal.

\section{Notation}

The following symbols are used in this paper:

$a, b=$ parameter obtained by regression analysis;

$B$ = flume width;

$d_{50}=$ median sediment size;

$D_{c}=$ column width or diameter of cylindrical pier

[Fig. 1(a)];

$D_{e}=$ equivalent diameter of complex pier;

$D_{e *}=$ maximum equivalent diameter of complex pier (calculated according to Coleman 2005);

$D_{p}=$ pile width [Fig. 1(a)];

$D_{p c}=$ pile cap width or diameter of cylindrical foundation [Fig. 1(a)];

$d_{s}=$ scour depth;

$d_{s c}=$ scour depth for uniform pier of width of column;

$d_{s e}=$ equilibrium scour depth;

$d_{s m}=$ scour depth measured at the end of the test;

$d_{\text {smMC }}=$ scour depth measured at time defined according to Melville and Chiew (1999);

$d_{s m 2}=$ scour depth measured at time defined according to Eq. (2);

$f_{l}=$ extension length of pile-cap face out from column face [Fig. 1(a)];

$f_{t}=$ extension width of pile-cap face out from column face [Fig. 1(a)];

$h=$ approach flow depth [Fig. 1(a)];

$H_{c}=$ level of top surface of pile cap above surrounding bed level [Fig. 1(a)];

$\left(H_{c} / T\right)_{\max }=$ pile-cap elevation at which the maximum equilibrium scour depth can be obtained;

$K_{\text {spc }}=$ pile-cap shape factor;

$L_{c}=$ column length [Fig. 1(a)];

$L_{p c}=$ pile-cap length [Fig. 1(a)];

$m=$ number of piles in line with flow [Fig. 1(a)];

$n=$ number of piles normal to the flow [Fig. 1(a)];

$S_{m}=$ pile spacing length (centerline-to-centerline)

[Fig. 1(a)];

$S_{n}=$ pile spacing width (centerline-to-centerline)

[Fig. 1(a)];

$t=$ time;

$T=$ pile-cap thickness [Fig. 1(a)];

$t_{d}=$ experiment duration;

$t_{\mathrm{dMS}}=$ experiment duration obtained by Eq. (2);

$U=$ mean velocity of the approach flow;

$U_{c}=$ critical flow velocity;

$\Delta d_{s}=$ increment of scour depth in $24 \mathrm{~h}$; and

$\sigma_{g}=$ geometric standard deviation of sediment sizes.

\section{References}

Alabi, P. D. (2006). "Time development of local scour at a bridge pier fitted with a collar." Master's Degree Thesis, Univ. of Saskatchewan, Saskatoon, Saskatchewan, Canada.

Arneson, L. A., Zevenbergen, L. W., Lagasse, P. F., and Clopper, P. E. (2012). "Evaluating scour at bridges (HEC-18)." Technical Rep. No. FHWA (Federal Highway Administration) HIF-12-003, Washington, DC. 
Ataie-Ashtiani, B., Baratian-Ghorghi, Z., and Beheshti, A. A. (2010). "Experimental investigation of clear-water local scour of compound piers." J. Hydraul. Eng., 10.1061/(ASCE)0733-9429(2010)136:6(343), 343-351.

Beheshti, A. A., and Ataie-Ashtiani, B. (2010). "Experimental study of three-dimensional flow field around a complex bridge pier." J. Eng. Mech., 10.1061/(ASCE)EM.1943-7889.0000073, 143-154.

Chabert, J. and Engeldinger, P. (1956). Etude des affouillements autour des piles des ponts, Laboratoire National d'Hydraulique, Chatou, France (in French).

Chiew, Y. M., and Melville, B. W. (1987). "Local scour around bridge piers." J. Hydraul. Eng., 25(1), 15-26.

Coleman, S. E. (2005). "Clearwater local scour at complex piers." J. Hydraul. Eng., 10.1061/(ASCE)0733-9429(2005)131:4(330), 330-334.

Dey, S., and Raikar, R. V. (2007). "Characteristics of horseshoe vortex in developing scour holes at piers." J. Hydraul. Eng., 10.1061/(ASCE) 0733-9429(2007)133:4(399), 399-413.

Ettema, R. (1980). "Scour at bridge piers." Rep. No. 216, Univ. of Auckland, Auckland, New Zealand.

Ferraro, D., Tafarojnoruz, A., Gaudio, R. and Cardoso, A. H. (2013). "Effects of pile cap thickness on the maximum scour depth at a complex pier." J. Hydraul. Eng., 10.1061/(ASCE)HY.1943-7900.0000704, 482-491.

Franzetti, S., Larcan, E., and Mignosa, P. (1982). "Influence of tests duration on the evaluation of ultimate scour around circular piers." Proc. Int. Conf. on the Hydraulic Modelling of Civil Engineering Structures, Cranfield, U.K.

Grimaldi, C., and Cardoso, A. H. (2010). "Methods for local scour depth estimation at complex bridge piers." Proc., 1st IAHR European Division Congress, Heriot-Watt Univ., Edinburgh, U.K.

Grimaldi, C., Gaudio, R., Calomino, F., and Cardoso, A. (2009). "Control of scour at bridge piers by a downstream bed sill." J. Hydraul. Eng., 10 .1061/(ASCE)0733-9429(2009)135:1(13), 13-21.

Jones, J. S. (1989). "Laboratory studies of the effects of footings and pile groups on bridge pier scour." Proc., 1st Bridge Scour Symp., TurnerFairbank Highway Research Center, FHWA, McLean, VA, 340-359.

Jones, J. S., Kilgore, R. T., and Mistichelli, M. P. (1992). "Effects of footing location on bridge pier scour." J. Hydraul. Eng., 10.1061/(ASCE)07339429(1992)118:2(280), 280-290.

Jones, J. S., and Sheppard, D. M. (2000). "Local scour at complex pier geometries." Proc., 2000 Joint Conf. on Water Resources Engineering and Water Resources Planning and Management, ASCE, Minneapolis, $\mathrm{MN}$.

Lança, R., Fael, C., Maia, R., Pêgo, J., and Cardoso, A. (2013). "Clearwater scour at pile groups." J. Hydraul. Eng., 10.1061/(ASCE)HY 1943-7900.0000770, 1089-1098.

Lu, J.-Y., Shi, Z.-Z., Hong, J.-H., Lee, J.-J., and Raikar, V. K. (2011). "Temporal variation of scour depth at nonuniform cylindrical piers." J. Hydraul. Eng., 10.1061/(ASCE)HY.1943-7900.0000272, 45-56.

Mashahir, M. B., Zarrati, A. R., and Rezayi, M. J. (2004). "Time development of scouring around a bridge pier protected by collar." Proc., 2nd Int. Conf. on Scour and Erosion, Meritus Mandarin, Singapore.

Melville, B. W., and Chiew, Y. M. (1999). "Time scale for local scour at bridge piers." J. Hydraul. Eng., 10.1061/(ASCE)0733-9429(1999) 125:1(59), 59-65.

Melville, B. W., and Raudkivi, A. J. (1996). "Effect of foundation geometry on bridge pier scour." J. Hydraul. Eng., 10.1061/(ASCE)0733-9429 (1996)122:4(203), 203-209.

Moreno, M., Maia, R., Couto, L., and Cardoso, A. (2012). "Evaluation of local scour depth around complex bridge piers." Proc., River Flow 2012, R. Murillo, ed., CRC Press, Boca Raton, FL, 935-942.

Neill, C. R. (1967). "Mean velocity criterion for scour of coarse uniform bed-material." Proc., 12th IAHR Congress, IAHR, Fort Collins, CO, $46-54$.

Parola, A. C., Mahavadi, S. K., Brown, B. M., and El-Khoury, A. (1996). "Effects of rectangular foundation geometry on local pier scour." J. Hydraul. Eng., 10.1061/(ASCE)0733-9429(1996)122:1(35), 35-40.

Salim, M., and Jones, J. S. (1996). "Scour around exposed pile foundations." Proc., North American Water and Environment Conf. '96, ASCE, Anaheim, CA.

Sheppard, D. M., Demir, H., and Melville, B. (2011). "Scour at wide piers and long skewed piers." National Cooperative Highway Research Program Rep. 682, Transportation Research Board, Washington, DC.

Sheppard, D. M., Melville, B., and Demir, H. (2014). "Evaluation of existing equations for local scour at bridge piers." J. Hydraul. Eng., 10.1061/(ASCE)HY.1943-7900.0000800, 14-23.

Sheppard, D. M., and Renna, R. (2010). Bridge scour manual, Florida Dept. of Transportation, Tallahassee, FL.

Umeda, S., Yamazaki, T., and Yuhi, M. (2010). "An experimental study of scour process and sediment transport around a bridge pier with foundation." Proc., Scour and Erosion, ASCE, San Francisco, CA, 66-75.

Yalin, M. S. (1971). Theory of hydraulic models, MacMillan Civil Engineering Hydraulics, Macmillan. 